\title{
PECULIARITIES OF INDIVIDUAL INDICATORS OF ANXIETY- DEPRESSIVE SYMPTOMS IN STUDENTS FROM MEDICAL UNIVERSITY IN THE PERIOD OF ALTERED PSYCHOEMOTIONAL STATUS
}

\author{
Ivan Romash ${ }^{1}$, Mukhailo Vynnyk ${ }^{1}$, Iryna Romash², Anna Polinyk ${ }^{3}$, Olena Yevchyk
}

${ }^{1}$ Department of Psychiatry, Narcology and Medical Psychology, Ivano-Frankivsk National Medical University (IFNMU), Ivano-Frankivsk, Ukraine

${ }^{2}$ Department of Propaedeutics of Internal Medicine, Ivano-Frankivsk National Medical University (IFNMU), Ivano-Frankivsk, Ukraine

35 year students of the Faculty of Medicine. Ivano-Frankivsk National Medical University (IFNMU), Ivano-Frankivsk, Ukraine

\begin{abstract}
Introduction: Scientists have shown that medical training itself is a risk factor in the occurrence and maintenance of symptoms of depression Aim: To investigate and evaluate the level of anxiety and depression among students of the Faculty of Medicine and the Faculty of Training of Foreign Citizens of IFNMU during a period of altered psycho-emotional state.

Materials and methods: To achieve the goal of the study, 106 medical students aged 19 to 25 years were questioned. In order to identify emotional disturbances, we used two clinical test methods: the Hospital Anxiety and Depression Scale (HADS) and the Montgomery-Asberg Depression Rating Scale (MADRS).

Conclusions: A study of the level of anxiety and depression among students of the medical faculty and the faculty of training foreign citizens during an altered psycho-emotional state confirms that the exams caused the appearance of protective mechanisms in the form of emotional and behavioral changes and disorders.
\end{abstract}

Key words: depression, anxiety, altered psychoemotional state.

Introduction: It is well known that medical students often encounter many difficulties during training in the medical program (Castaldelli-Maia et.al.,2012). If these difficulties are ignored, they can cause additional stress and affect their academic performance, which are already under very high pressure (Dyrbye, L.N. et.al.,2011). Stress can jeopardize future professionalism. It is also known, that stress leads to emotional disturbances and suicidal ideas (Alexandrino-Silva C. et.al.,2009). There is no doubt that the difficulties associated with academic activity affect their functioning. Scientists have shown that medical training itself is a risk factor in the occurrence and maintenance of symptoms of depression. In addition, some scientific papers reported that various processes associated with competition in admission to medical universities, the first and subsequent contacts with death, pathological processes, and fear of acquiring illnesses caused 
emotional experiences among medical students (Baldassin S. et.al.,2012). According to other scientific data, due to their age characteristics, students are dreamers, idealistic about studying, hard to adapt to new requirements, inadequately assess their capabilities, and even feel their own failure. As a result, dissatisfaction with studies is formed, indifference to their duties is growing. There are signs of depersonalization, indicating the development of emotional burnout, depression. Especially often depression and emotional burnout are common among those studying in the medical specialty. Sergio Baldassini (2012), leading a team of scientists who conducted a study of 481 medical students at a private medical school in Brazil, notes that they often suffered from depression, especially during the internship. In his research, he revealed the extent of this problem and made a detailed analysis of the symptoms. According to Baldassini, "often before going to practice students are afraid that they" know nothing "and are not sure about the physical examination of other people" (Baldassin S. et.al.,2012).

The objective of the research was to investigate and evaluate the level of anxiety and depression among students of the Faculty of Medicine and the Faculty of Training of Foreign Citizens of IFNMU during a period of altered psychoemotional state.

Materials and methods: To achieve the goal of the study, 106 medical students aged 19 to 25 years were questioned, among them 26 young men and 80 girls. Students were surveyed in the spring and winter, during the preparation of students for tests, exams, final module controls, that is, during a period of altered psychoemotional state. We studied the effects of intensified learning on student anxiety and stress. During the study, the ethical principles of the Helsinki Declaration of the World Medical Association were adhered to. Testing was exclusively voluntary. In order to identify emotional disturbances, we used two clinical test methods: the Hospital Anxiety and Depression Scale (HADS) and the Montgomery-Asberg Depression Rating Scale (MADRS) (Zigmond A.S. et.al., 1987; Svanborg P. A. et.al.,2001) .

Results and discussion. After a survey and analysis of the results on the HADS and MADRS scales, we found a clear correlation between increased learning during an altered psycho-emotional state and the severity of anxietydepressive symptoms in medical students, which was manifested by an increase in anxiety and different degrees mood disorders .

Based on the results of the survey on this scale, during the period of the altered psycho-emotional state, the normal level of anxiety-depressive symptoms (0-7 points on the scale) was found in $18.43 \%$ of students of the medical faculty and in $33.35 \%$ of students of the Faculty of Training Foreign Citizens. Symptoms of "borderline" conditions (8-10 points on a scale) were found in $54.48 \%$ and $31.6 \%$ of students of the medical faculty and students of the Faculty of Training Foreign Citizens, respectively. Clinically expressed anxiety and depression (11-21 points) were found in $27.09 \%$ of medical students and in $35.05 \%$ of foreign students.

In the gender distribution, among students of the medical faculty, the normal level of anxiety and depression during preparation for passing modular controls is more common among girls, accounting for $20.8 \%$, compared to $15.5 \%$ among males. It is worth noting that the symptoms of "borderline" conditions and the level of clinically pronounced anxiety and depression were higher among male students and amounted to $55.25 \%$ and $28.75 \%$, respectively. In a student current, 
"borderline" conditions are noted in $53.6 \%$ of cases, and clinically pronounced anxiety-depressive symptoms in $25.4 \%$.

As for the students of the Faculty of Training of Foreign Citizens, the picture of the sexual distribution is somewhat different, namely: the symptoms of "borderline" conditions were higher among girls - 44.0\%, while among men $19.25 \%$. However, male students among foreign students had a high level of clinically pronounced anxiety and depression - $38.45 \%$, and among students it was slightly lower $-30.0 \%$.

The results of the clinical interview indicate depressive spectrum disorders among Ukrainian students of the medical faculty. Normal indicators, that is, the absence of depressive symptoms, were found in $76.4 \%$ of girls and in $76.9 \%$ of children. Signs of moderate depression were found in $9.02 \%$ of female students and in $1.2 \%$ of male students. Progressive depression in both sexes was manifested at almost the same level: $14.5 \%$ in women and $15.3 \%$ in men. It is worth noting that the symptoms of severe depression or a major depressive episode were observed in males and amounted on $6.6 \%$ of cases, among women this figure was only $0.08 \%$.

After processing the data from a survey of students of the Faculty of Training Foreign Citizens, we received the following indicators: $64.0 \%$ of students and $46.18 \%$ of male students did not have depressive symptoms; We found signs of moderate depression in $24.2 \%$ of girls and in $45.08 \%$ of boys; progressive depression - $11.8 \%$ among women and $8.74 \%$ among men. It should be noted that the symptoms of severe depression or a major depressive episode among students of the students of the Faculty of Training Foreign Citizens were not observed.

Conclusions: Thus, the study confirmed that the exam, as a stressful moment of the external identity test, caused the emergence of protective mechanisms in medical students in the form of emotional and behavioral changes and disorders. The results obtained indicate the presence of adaptation disorders during the period of the altered psychoemotional status in all the studied groups.

\section{References:}

Castaldelli-Maia J.M.,Martins S.S., Bhugra D. et.al.(2012) Does Ragging Play a Role in Medical Student Depression - Cause or Effect? Journal of Affective Disorders, 139 (3), 291-297.

Dyrbye, L.N., Harper, W., Durning, S.J. et.al. (2011) Patterns of distress in US medical students Medical Teacher, 33 (10), 834-839.

Alexandrino-Silva C., Pereira, M.L., Bustamante, C. et. al. (2009) Suicidal ideation among students enrolled inhealthcare training programs: a cross-sectional study. Revista Brasileira de Psiquiatria, 31 (4),338-344. 
Baldassin S. Silva N., Correa de Toledo T. Ferraz Alves et.al. (2012) Depression in medical students: Cluster symptoms and management. Journal of Affective Disorders, 50(1).

Zigmond A.S., Snaith RP. (2012) The hospital anxiety and depression scale. Acta Psychiatr Scand, 67(6), 361-70.

Svanborg P. A., Asberg M. (2001) A comparison between the Beck Depression Inventory (BDI) and the self-rated version of the Montgomery-Asberg Depression Rating Scale (MADRS). $J$ Affect Dis., 64, 203-16

Keywords: depression, anxiety, altered psychoemotional state 